$\begin{array}{ll}\text { Research Square } & \begin{array}{l}\text { Preprints are preliminary reports that have not undergone peer review. } \\ \text { They should not be considered conclusive, used to inform clinical practice, } \\ \text { or referenced by the media as validated information. }\end{array}\end{array}$

\title{
Irritable bowel syndrome among Jordanian medical students: Prevalence and associated factors
}

Khaled Ali Jadallah ( $\sim$ khaled-j@just.edu.jo )

King Abdullah University Hospital, Jordan University of Science and Technology https://orcid.org/0000-0001-9177-0980

Moawiah Mohammad Khatatbeh

Yarmouk University

Enas Walid Sarsak

King Abdullah University Hospital

Aroob Nabil Sweidan

King Abdullah University Hospital

Baraa F Alzu'bi

King Abdullah University Hospital

Research article

Keywords: Irritable bowel syndrome, Rome III criteria, Jordan; lifestyle, Medical students, Prevalence

Posted Date: July 16th, 2020

DOI: https://doi.org/10.21203/rs.3.rs-42057/v1

License: @) (7) This work is licensed under a Creative Commons Attribution 4.0 International License. Read Full License 


\section{Abstract \\ Background}

The literature on the prevalence of irritable bowel syndrome (IBS) and its correlates in Middle Eastern countries is scarce. This study aimed at investigating the prevalence of IBS and its associated factors among Jordanian medical students.

\section{Methods}

We conducted a cross-sectional study at two medical faculties in northern Jordan. Using convenience sampling, we recruited 1094 medical students. Participants completed an anonymous semi-structured questionnaire inquiring about socio-demographic, lifestyle, and clinical characteristics, as well as IBS symptoms. We used the Rome III criteria to diagnose IBS and the Hospital Anxiety and Depression Scale (HADS) to identify anxiety and depression. The chisquare test was used to determine differences between categorical variables and stepwise logistic regression was used to measure the association between IBS and its risk factors.

\section{Results}

The prevalence of IBS in our sample was $30.9 \%$. Binary logistic regression analysis of factors associated with IBS indicated having a family history of IBS as a strong predictor of the disease (OR $=8.09 ; \mathrm{Cl}: 5.84-11.19)$. Students at second and third-year levels of their study had ORs of about 4 (Cl: $2.20-6.54)$ and 3 (Cl: $1.70-5.30)$ of suffering from IBS, respectively, as compared to students at first-year level $(p=0.001)$. Increased anxiety score (OR = 1.88; Cl: $1.30-2.71)$, poor sleep quality $(\mathrm{OR}=1.76 ; \mathrm{Cl}: 1.13-2.76)$, female gender $(\mathrm{OR}=1.59 ; \mathrm{Cl}: 1.14-2.20)$ and living in a school dormitory $(\mathrm{OR}=1.35 ; \mathrm{Cl}$ : $1.00-1.84)$ were significantly associated with IBS $(p<0.05)$. Conversely, consumption of junk food, BMI of participants, and physical inactivity were not significantly associated with IBS occurrence.

\section{Conclusions}

Irritable bowel syndrome is a highly prevalent disorder in a university-based population in the Jordanian context, with several modifiable and non-modifiable factors being associated with its occurrence. A better understanding of the associated risk factors is crucial for a holistic therapeutic approach. Longitudinal studies are necessary to assess whether this association is causal.

\section{Introduction}

Irritable bowel syndrome (IBS) is a chronic functional gastrointestinal disorder characterized by recurrent abdominal pain and altered bowel habits. The Rome III criteria are the most widely used to diagnose IBS [1]. Studies using the Rome III criteria report a prevalence of IBS in Western countries in the range of 10 to $20 \%$ [2], whereas the prevalence in the Far East region ranges from 1 to $10 \%$ [3], and reaches $21 \%$ in South America [2]. Studies from developing countries, including Jordan, are scarce [4].

The prevalence of IBS varies by socioeconomic factors, gender, and age [2]. In developed countries, women are reported to be 2-4 times more likely to have IBS compared to men [2]. Irritable bowel syndrome is more prevalent among adolescents and declines with age. Several studies report that the odds of having IBS are higher among those younger than 50 years compared to those older than 50 years of age [2,5]. Jordan is a Middle Eastern, middle-income country with a population of about ten million, with one half the population composed of adolescents and young adults (age 15-49 years) [6]. Therefore, it is anticipated that the prevalence of IBS in the general population is high.

Lifestyle factors such as unhealthy eating habits (junk or fast food), smoking, alcohol consumption, and physical inactivity have been linked to IBS [7,8]. Irritable bowel syndrome has been also associated with psychological factors such as stress, depression, and anxiety [9, 10]. Additionally, genetic factors have been implicated, with $33 \%$ of patients with IBS reporting a positive family history [2]. Irritable bowel syndrome is associated with a considerable reduction in the quality of life, accompanied by significant socioeconomic and psychological consequences [11, 12]. In the clinical setting, IBS represents a large proportion of gastrointestinal workload in both primary and secondary care [12].

University students, particularly medical students, are more likely to be limited in terms of access to healthy foods and subjected to the substantial stress load that accompanies their studies and examinations. Thus, they are supposedly more prone to develop IBS than other population subgroups [13]. A recent study of Lebanese university students reported an overall prevalence of $20 \%$ using the Rome III criteria [12]. This study aimed to assess the prevalence of IBS among Jordanian medical students and to investigate the socio-demographic, lifestyle, and clinical factors associated with IBS. A better understanding of IBS correlates is expected to improve our therapeutic approach to IBS patients.

\section{Methods}

Between January 2019 and April 2019, we conducted a cross-sectional study at the Faculty of Medicine, Jordan University of Science and Technology, and the Faculty of Medicine, Yarmouk University, both located in Northern Jordan. Participants (1st to 6th -year medical students) were invited to complete an anonymous semi-structured questionnaire inquiring about demographic, social, lifestyle, and clinical characteristics, as well as IBS symptoms, if any. In this study, we recruited a convenience sample of 1094 medical students. To determine the presence of IBS, we used the Rome III criteria. The questionnaire 
consisted of three parts: the first part included questions on demographic and socioeconomic characteristics of participants; the second part explored the clinical and lifestyle factors; the third part consisted of questions aimed to determine the presence of IBS based on the Rome III criteria. Additionally, we used the validated Hospital Anxiety and Depression Scale (HADS) to evaluate the presence of anxiety and/or depression in our study subjects. Despite the established validity of the instruments used, a pilot testing analysis on 30 participants was carried out and revealed Cronbach's alpha scores of 0.83 and 0.88 for both Rome III criteria and HADS instruments, respectively. Both scales were presented to participants in the English language as English is the formal language of study in all medical colleges in Jordan. Furthermore, the objectives of the study were explained in detail to the participants by trained medical residents. All participants provided a verbal informed consent (approved by our institutional review board). Students with significant comorbidities or a definite or suspected history of inflammatory bowel disease, celiac disease, or peptic ulcer disease were excluded from participating in the survey.

\section{Rome III criteria}

The diagnosis of IBS was based on Rome III criteria for Functional Gastrointestinal Disorders [1, 14]. This diagnostic tool defines IBS as recurrent abdominal pain or discomfort for at least 3 days/month during last 3 months associated with two or more of the following features: (1) Improvement with defecation, (2) and/or onset associated with a change in frequency of stool, (3) and/or onset associated with a change in form (appearance) of stool.

\section{Hospital Anxiety and Depression Scale (HADS)}

The HADS is commonly used by physicians to determine the level of anxiety and depression that an individual is experiencing [15]. The HADS is a fourteenitem diagnostic tool, with seven of the items related to anxiety and seven related to depression. Each item in the questionnaire is scored from $0-3$, and this means that an individual can score between 0 and 21 for either anxiety or depression with the following categories: $0-7=$ Normal; $8-10=$ Borderline; $11-21=$ Abnormal (case).

\section{Sample size calculation}

The sample size was calculated based on the probability that the prevalence of IBS in Jordan is $20 \%$ and the error in the estimate is $\pm 3.4 \%$, with a $95 \%$ confidence interval. Based on that assumption, the required sample size was 532

\section{Data analysis}

We analyzed all data using SPSS (Version 20 for Windows). Frequency distribution and descriptive statistics were calculated. We compared questionnaire responses using the chi-square test. A $p$-value of $<0.05$ was used to indicate statistical significance in all cases. Potential risk factors for IBS with a $p$-value $\leq$ 0.25 in the cross-tabulation analysis were subjected to a stepwise binary logistic regression analysis.

\section{Results}

A total of 1135 students participated in the study. Questionnaires with complete data were returned by 1094 participants whereas 31 questionnaires were excluded from analysis due to insufficient data (response rate $=96.4 \%$ ). Our study population age ranged from 18 to 24 years. As illustrated in Table 1 , female participants were slightly more represented than males in the study ( $54.3 \%$ females; $45.7 \%$ males).

Concerning the lifestyle of study participants, most of the participants had junk food 1-3 times per week. Concerning sleep patterns, about $40 \%$ and $14 \%$ of participants reported having fair and poor sleep quality, respectively. About $70 \%$ of them did not practice physical exercise regularly or practiced for less than 30 minutes per day.

As shown in Table 2, most demographic and lifestyle factors had significant statistical associations with IBS. Conversely, the BMI of participants, consumption of junk food, and physical inactivity were not significantly associated with IBS.

To identify factors associated with IBS, all risk factors with a $p$-value $\leq 0.25$ in the univariate analysis were included in a stepwise binary logistic regression analysis. Table 3 illustrates the statistically significant risk factors in the last regression model. Participants with a positive family history of IBS were 8 times more likely to have the disorder compared to their counterparts with negative family history. An increased anxiety score was associated with IBS among participants, whereas depression was not. Interestingly, the odds of having IBS increased among second and third-year medical students and then declined among $4^{\text {th }}, 5^{\text {th }}$, and $6^{\text {th }}$-year students compared to those in the $1^{\text {st }}$-year study level.

\section{Discussion}

To our knowledge, this is the first study using the Rome III criteria of the prevalence and the associated factors of IBS in a cohort of Jordanian medical students. The overall prevalence of IBS in the study sample was $30.9 \%$, which is much higher than that in Western populations. This result is similar to results from Saudi Arabia reporting that one-third of the paramedical students were diagnosed as having IBS, based on Rome-III criteria [16]. In a study from Colombia, the prevalence of IBS among university students was 24\% [17]. In agreement with our study, results inferred from a recent Lebanese study found that individuals aged less than 30 years were at a higher risk of having IBS [18]. The high prevalence of IBS in this subgroup of the population could be attributed to a higher level of anxiety, which was a common finding in most of the reported studies.

In the current study, females had a higher risk for having IBS compared to males. This result is consistent with results from a recent study of the prevalence of IBS among Pakistani medical students using ROME III criteria [19]. Similar results were reported from Suadi Arabia [16], Iraq [20], and Nigeria [21]. Results of the current study and other studies concerning gender differences in having IBS agree with a meta-analysis review which concluded that female sex hormones may affect the severity of IBS symptoms [22]. 
Congruent with our findings of a higher risk for IBS among students who live in school dormitory compared to those living with their families, studies from Lebanon [7] and Malaysia [23] reported similar results. Arguably, a higher prevalence of IBS in students who live with their families may be due to shared family environmental exposures.

A positive family history of IBS places participants at higher odds of having IBS. This trend was observed among university students in Saudi Arabia [16] and South Korea [24]. Such finding is supported by the notion that genetic factors are important for the familial clustering of IBS and familial odds for having IBS among first-degree relatives [25].

Concerning sleep patterns, our results reported an association between IBS and poor sleep quality. Consistent with our results, this finding was reported by medical students from Saudi Arabia [16]. In a more recent study of 956 individuals with sleep disturbance (using the Pittsburgh Sleep Quality Index), the authors found that sleep disturbance was significantly associated IBS [26]. In the current study, participants with IBS had significantly higher levels of anxiety than their counterparts. This result was reported by Nigerian medical students [21] and university students in South Korea[24]. A recent meta-analysis review concluded that anxiety level is higher in patients with IBS than in healthy controls [10]. Such a result is expected as IBS is a stress-sensitive disorder [27]. Therefore, anxiety symptoms should be systematically verified and treated in IBS patients, as psychological factors are important determinants of symptoms severity and persistence, willingness to seek treatment and response to therapy. Yet, longitudinal studies of the effect of psychiatric evaluation and treatment of IBS patients are warranted.

Concerning IBS according to study level, in the current study second and 3rd -year medical students were at greater risk compared to freshman students and those in the 4th, 5th, and 6th -year students. This finding is congruent with findings from an Iranian study [28]. In that study, IBS was more prevalent in the 1st and 2nd year compared to 4th and 5th -year medical students. Conversely, a Canadian study from Schulich School of Medicine and Dentistry in Ontario found an insignificant statistical difference between preclinical and clerkship medical students with IBS [29]. Arguably, the study level seems to contribute to the prevalence of IBS among medical students. However, a clear trend has not been firmly established between different levels. Students in their 2 nd and 3 rd -year level encounter the most challenging time due to their introduction to a new environment with difficult situations aggravated by the nature of integrative modular systems of study during these two years. We believe that fear of failing exams and anxiety levels increase, thus leading to a significant increase in IBS prevalence.

The strength of this research is the high questionnaire response rate and the large sample size, which substantiate the validity of our findings. However, our study had two limitations. First, the survey was restricted to medical students, which might influence the generalizability of our results to the Jordanian population. Second, the diagnosis of IBS was based on self-reporting questionnaires, without using any objective tests to exclude organic disorders.

\section{Conclusions}

This study found a high prevalence of IBS among Jordanian medical students. Several modifiable and non-modifiable risk factors for IBS have been identified. Owing to the multifaceted pathophysiology of this disorder, an improved understanding of the associated risk factors is required for a holistic therapeutic approach. We believe that findings from this study have important implications for national programs designed to improve academic performance, stress management and overall quality of life among students suffering from IBS. Finally, longitudinal surveys are needed to establish whether this putative association is causal.

\section{Abbreviations}

IBS: Irritable bowel syndrome; HADS: Hospital anxiety and depression scale; BMI: Body mass index

\section{Declarations}

\section{Ethics approval and consent to participate}

The study was approved by the Institutional Review Board (IRB) at King Abdullah University Hospital and the Jordan University of Science and Technology (Grant Number: 20180165). Verbal consent was obtained from all participants and approved by the IRB, and all study procedures were conducted according to the World Medical Association Declaration of Helsinki.

\section{Consent for publication}

Not applicable.

\section{Availability of data and materials}

The datasets used and analysed during the current study are available from the corresponding author on reasonable request.

\section{Competing interests}

The authors declare that they have no competing interests.

\section{Funding}

Not applicable. 
K.J. and M.K. designed this study and drafted the manuscript. M.K. performed the statistical data analysis. K.J. reviewed the manuscript for intellectual content. E.S, A.S., and B.A. collected the data, reviewed the literature, and contributed to the writing of the manuscript. All authors have read and approved the final version of the manuscript, and provided critical feedback.

\section{Acknowledgements}

Not applicable.

\section{References}

1. Drossman DA. The functional gastrointestinal disorders and the Rome III process. Gastroenterology. 2006;130(5):1377-1390. [PMID:16678553. https://doi.org/10.1053/j.gastro.2006.03.008.

2. Lovell RM, Ford AC. Global prevalence of and risk factors for irritable bowel syndrome: a meta-analysis. Clin Gastroenterol Hepatol. 2012;10(7):712-721 e714.

[PMID: 22426087. https://doi.org/10.1016/j.cgh.2012.02.029.

3. Miwa H. Prevalence of irritable bowel syndrome in Japan: Internet survey using Rome III criteria. Patient Prefer Adherence. 2008;2:143-147.

4. Altamimi EM, Al-Safadi MH. Abdominal Pain-Predominant Functional Gastrointestinal Disorders in Jordanian School Children. Gastroenterology Res. 2014;7(5-6):137-142. [PMID:27785284 PMCid:PMC5040537.

https://doi.org/10.14740/gr627w.

5. Farzaneh N, Ghobaklou M, Moghimi-Dehkordi B, Naderi N, Fadai F. Effects of demographic factors, body mass index, alcohol drinking and smoking habits on irritable bowel syndrome: a case control study. Ann Med Health Sci Res. 2013;3(3):391-396. [PMID:24116320 PMCid:PMC3793446.

https://doi.org/10.4103/2141-9248.117958.

6. http://jorinfo.dos.gov.jo/PXWeb2014R2/Selection.aspx?

px_path=Population\%20and\%20Housing_Demographic\%20Statistics\&px_tableid=Table\%202.px\&px_language=en\&px_db=Population\%20and\%20Housing\&rx d04f-4689-ace3-8f29bf1f19da.

7. Costanian C, Tamim H, Assaad S. Prevalence and factors associated with irritable bowel syndrome among university students in Lebanon: findings from a cross-sectional study. World J Gastroenterol. 2015;21(12):3628-3635. [PMID:25834330 PMCid:PMC4375587. https://doi.org/10.3748/wjg.v21.i12.3628.

8. Khayyatzadeh SS, Esmaillzadeh A, Saneei P, Keshteli AH, Adibi P. Dietary patterns and prevalence of irritable bowel syndrome in Iranian adults. Neurogastroenterol Motil. 2016;28(12):1921-1933. [PMID:27324285.

https://doi.org/10.1111/nmo.12895.

9. Fond G, Loundou A, Hamdani N, et al. Anxiety and depression comorbidities in irritable bowel syndrome (IBS): a systematic review and meta-analysis. Eur Arch Psychiatry Clin Neurosci. 2014;264(8):651-660. [PMID: 24705634.

https://doi.org/10.1007/s00406-014-0502-z.

10. Lee C, Doo E, Choi JM, et al. The Increased Level of Depression and Anxiety in Irritable Bowel Syndrome Patients Compared with Healthy Controls: Systematic Review and Meta-analysis. J Neurogastroenterol Motil. 2017;23(3):349-362. [PMID:28672433 PMCid:PMC5503284.

https://doi.org/10.5056/jnm16220.

11. Whitehead WE, Burnett CK, Cook EW, 3rd, Taub E. Impact of irritable bowel syndrome on quality of life. Dig Dis Sci. 1996;41(11):2248-2253.

[PMID:8943980

https://doi.org/10.1007/BF02071408.

12. Jones RH. Clinical economics review: gastrointestinal disease in primary care. Aliment Pharmacol Ther. 1996;10(3):233-239. [PMID:8791945. https://doi.org/10.1111/j.0953-0673.1996.00233.x.

13. Dong YY, Chen FX, Yu YB, et al. A school-based study with Rome III criteria on the prevalence of functional gastrointestinal disorders in Chinese college and university students. PLoS One. 2013;8(1):e54183. [PMID:23349820 PMCid:PMC3548818. https://doi.org/10.1371/journal.pone.0054183.

14. Longstreth GF, Thompson WG, Chey WD, Houghton LA, Mearin F, Spiller RC. Functional bowel disorders. Gastroenterology. 2006;130(5):1480-1491 [PMID: 16678561. https://doi.org/10.1053/j.gastro.2005.11.061.

15. Zigmond AS, Snaith RP. The hospital anxiety and depression scale. Acta Psychiatr Scand. 1983;67(6):361-370. [PMID: 6880820.

https://doi.org/10.1111/j.1600-0447.1983.tb09716.x.

16. Ibrahim N, Al-Jamhoor S, Ashor N, et al. Irritable Bowel Syndrome among Paramedical Students, King Abdulaziz University, Jeddah, Saudi Arabia. Journal of Advances in Medicine and Medical Research. 2018;25(6). 
https://doi.org/10.9734/JAMMR/2018/39233.

17. Canon M, Ruiz AJ, Rondon M, Alvarado J. Prevalence of irritable bowel syndrome and health-related quality of life in adults aged 18 to 30 years in a Colombian University: an electronic survey. Ann Gastroenterol. 2017;30(1):67-75. [PMID:28042240 PMCid:PMC5198249.

https://doi.org/10.20524/aog.2016.0093.

18. Chatila R, Merhi M, Hariri E, Sabbah N, Deeb ME. Irritable bowel syndrome: prevalence, risk factors in an adult Lebanese population. BMC Gastroenterol. 2017;17(1):137. [PMID:29197339 PMCid:PMC5712083.

https://doi.org/10.1186/s12876-017-0698-2.

19. Iftikhar B, Naveed H, ur Rehman Khalil K, ur Rehman H, Khushbaght. Prevalence of Irritable Bowel Syndrome and it's Risk Factors Among Medical Students of Peshawar, Pakistan. Pakistan Journal of Medical Research. 2018;57(1).

20. A.Sadiq M, A.Salih A. The prevalence of irritable bowel syndrome and associated factors among a sample of medical college students in Baghdad. Journal of Medical Case Reports and Reviews 2019;2 (2).

21. Jemilohun A, Abayomi O, Adebayo P. Prevalence of Irritable Bowel Syndrome, Psychological III-Health and Health-Seeking Behavior in a Population of Nigerian Medical Students. Journal of Advances in Medicine and Medical Research. 2019;25(4). https://doi.org/10.9734/JAMMR/2018/39235.

22. Adeyemo MA, Spiegel BM, Chang L. Meta-analysis: do irritable bowel syndrome symptoms vary between men and women? Aliment Pharmacol Ther. 2010;32(6):738-755. [PMID: 20662786 PMCid:PMC2932820.

https://doi.org/10.1111/j.1365-2036.2010.04409.x.

23. AbdelSalam IRS, A. M. M. The Prevalence of Irritable Bowel Syndrome (IBS) in a Private-University in Malaysia, and Its Associated Factors Including Stress, Depression and Anxiety. Asian Journal of Medicine and Health. 2018;13(2).

https://doi.org/10.9734/AJMAH/2018/45604.

24. Seo JY PJ, Jung YM , Lee HJ. Prevalence and Factors related to Irritable Bowel Syndrome in University Students. Journal of Korean Academy of Fundamentals of Nursing. 2018 25(4). https://doi.org/10.7739/jkafn.2018.25.4.282.

25. Waehrens R, Ohlsson H, Sundquist J, Sundquist K, Zoller B. Risk of irritable bowel syndrome in first-degree, second-degree and third-degree relatives of affected individuals: a nationwide family study in Sweden. Gut. 2015;64(2):215-221. [PMID: 24694578. https://doi.org/10.1136/gutjnl-2013-305705.

26. Lei WY, Chang WC, Wong MW, et al. Sleep Disturbance and Its Association with Gastrointestinal Symptoms/Diseases and Psychological Comorbidity. Digestion. 2019;99(3):205-212. [PMID:30179863. https://doi.org/10.1159/000490941.

27. Qin HY, Cheng CW, Tang XD, Bian ZX. Impact of psychological stress on irritable bowel syndrome. World J Gastroenterol. 2014;20(39):14126-14131. [PMID:25339801 PMCid:PMC4202343. https://doi.org/10.3748/wjg.v20.i39.14126.

28. Ghannadi K, Emami R, Bashashati M, Tarrahi MJ, Attarian S. Irritable bowel syndrome: an epidemiological study from the west of Iran. Indian J Gastroenterol. 2005;24(5):225-226.

29. Grundmann O, Yoon SL. Irritable bowel syndrome: epidemiology, diagnosis and treatment: an update for health-care practitioners. J Gastroenterol Hepatol. 2010;25(4):691-699. [PMID:20074154. https://doi.org/10.1111/j.1440-1746.2009.06120.x.

\section{Tables}


Table 1: Demographic, lifestyle and clinical characteristics of study population ( $n=1094)$

Characteristic n (\%)

\section{Gender}

Male

500 (45.7)

Female

594 (54.3)

Study level/year

1

297 (27.1)

2

228 (20.8)

3

146 (13.3)

4

140 (12.8)

5

182 (16.7)

6

101 (9.3)

BMI

Underweight

78 (7.2)

Normal

655 (60.1)

Overweight

267 (24.5)

Obese

89 (8.2)

Marital status

Single

1074 (98.2)

Married

$20(1.8)$

Living condition

With family

633 (57.9)

School dormitory or private

461 (42.1)

Monthly income/JD

Less than 700

236 (21.6)

700-1499

309 (28.2)

$1500+$

549 (50.2)

Participants' perception of having IBS

No

765 (69.9)

Yes

329 (30.1)

Diagnosis with IBS

No

756 (69.1)

Yes

338 (30.9)

Depression score

Normal

627 (57.3)

Borderline

261 (23.9)

Case

206 (18.8)

Anxiety score

Normal

544 (49.7)

Borderline

282 (25.8)

Case

268 (24.5)

Sleep patterns

Good

508 (46.4)

Fair

436 (39.9)

Poor

150 (13.7)

Junk food meals /week 
BMI: Body mass index; IBS: Irritable bowel syndrome 
Table 2: Cross-tabulation of demographic and lifestyle factors associated with IBS* among medical students (n=1094)

\begin{tabular}{|c|c|c|c|}
\hline \multirow[t]{3}{*}{ Variable } & \multicolumn{2}{|c|}{ IBS } & \multirow[t]{3}{*}{$p$-value } \\
\hline & Yes & No & \\
\hline & n (\%) & n (\%) & \\
\hline Gender & & & .011 \\
\hline Female & $203(60.1)$ & 391 (51.7) & \\
\hline Male & 135 (39.9) & 365 (48.3) & \\
\hline Study level/year & & & .001 \\
\hline 1 & $78(23.1)$ & $219(29.0)$ & \\
\hline 2 & $63(18.6)$ & 165 (21.8) & \\
\hline 3 & $54(16.0)$ & $92(12.2)$ & \\
\hline 4 & $40(11.8)$ & $100(13.2)$ & \\
\hline 5 & $55(16.3)$ & 127 (16.8) & \\
\hline 6 & $48(14.2)$ & $53(7.0)$ & \\
\hline BMI & & & .136 \\
\hline Underweight & $21(6.2)$ & $57(7.6)$ & \\
\hline Normal & 192 (56.8) & 463 (61.7) & \\
\hline Overweight & $98(29.0)$ & $169(22.4)$ & \\
\hline Obese & $27(8.0)$ & $62(8.3)$ & \\
\hline Physical activity & & & .260 \\
\hline No & $193(57.1)$ & 459 (60.7) & \\
\hline Yes & 145 (42.9) & 297 (39.3) & \\
\hline Living conditions & & & .010 \\
\hline With family & $176(52.1)$ & 457 (60.4) & \\
\hline School dormitory or private & 162 (47.9) & 299 (39.6) & \\
\hline Junk food meals / week & & & .529 \\
\hline Never & $46(13.6)$ & $85(11.3)$ & \\
\hline $1-3$ & 242 (71.8) & 559 (74.3) & \\
\hline $4+$ & $49(14.5)$ & $107(14.4)$ & \\
\hline Sleep patterns & & & .001 \\
\hline Good & 131 (38.8) & 377 (49.9) & \\
\hline Fair & $146(43.2)$ & $290(38.4)$ & \\
\hline Poor & $61(18.0)$ & 89 (11.7) & \\
\hline Family history of IBS & & & .001 \\
\hline No & 157 (46.6) & $650(86.1)$ & \\
\hline Yes & $180(53.4)$ & 105 (13.9) & \\
\hline Depression score & & & .003 \\
\hline Normal & $171(50.6)$ & $456(60.3)$ & \\
\hline Borderline & $85(25.1)$ & 176 (23.3) & \\
\hline Case & $82(24.3)$ & $124(16.4)$ & \\
\hline Anxiety score & & & .001 \\
\hline Normal & $139(41.1)$ & $405(53.6)$ & \\
\hline Borderline & $84(24.9)$ & $198(26.2)$ & \\
\hline Case & $115(34.0)$ & $153(20.2)$ & \\
\hline
\end{tabular}


Table 3. Binary logistic regression analysis of factors associated with IBS* $(n=1094)$

\begin{tabular}{|c|c|c|c|c|}
\hline \multirow[t]{2}{*}{ Variable } & \multirow[t]{2}{*}{ OR } & \multicolumn{2}{|c|}{ 95\% C.I } & \multirow[t]{2}{*}{$p$-value } \\
\hline & & Lower & Upper & \\
\hline \multicolumn{5}{|l|}{ Gender } \\
\hline Male & $1 * *$ & & & 0.005 \\
\hline Female & 1.59 & 1.14 & 2.20 & \\
\hline \multicolumn{5}{|l|}{ Study level/year } \\
\hline 1 & $1 * *$ & & & 0.001 \\
\hline 2 & 3.79 & 2.20 & 6.54 & \\
\hline 3 & 3.00 & 1.70 & 5.30 & \\
\hline 4 & 2.01 & 1.11 & 3.65 & \\
\hline 5 & 2.37 & 1.28 & 4.39 & \\
\hline 6 & 2.61 & 1.46 & 4.67 & \\
\hline Family history of IBS & & & & 0.001 \\
\hline No & $1 * *$ & & & \\
\hline Yes & 8.09 & 5.84 & 11.19 & \\
\hline \multicolumn{5}{|l|}{ Living condition } \\
\hline With family & $1 * *$ & & & 0.052 \\
\hline School dormitory or private & 1.35 & 1.00 & 1.84 & \\
\hline \multicolumn{5}{|l|}{ Sleep pattern } \\
\hline Good & $1 * *$ & & & 0.016 \\
\hline Fair & 1.20 & 0.77 & 1.88 & \\
\hline Poor & 1.76 & 1.13 & 2.76 & \\
\hline \multicolumn{5}{|l|}{ Anxiety score } \\
\hline Normal & $1 * *$ & & & 0.003 \\
\hline Borderline & 1.55 & 1.03 & 2.33 & \\
\hline Case & 1.88 & 1.30 & 2.71 & \\
\hline
\end{tabular}

*Irritable bowel syndrome; ** Reference for other categories within each variable. 